\title{
Inconsciente e Linguagem Comum na Teoria Freudiana ${ }^{1}$
}

\author{
Reinaldo Furlan ${ }^{2}$ \\ Universidade de São Paulo, Ribeirão Preto
}

\begin{abstract}
RESUMO - Este ensaio procura explorar a relação entre a linguagem comum e a noção freudiana de inconsciente. Procura, sobretudo, estabelecer pontos em comum entre as semânticas do inconsciente e das práticas lingüísticas socialmente organizadas, para, por fim, apontar para o lugar de sua provável ruptura.
\end{abstract}

Palavras-chave: Freud; inconsciente; linguagem comum.

\section{Unconscious and Common Language in Freudian Theory}

\begin{abstract}
The present paper aims to explore the connection between common language and Freud's notion of unconscious. It is specially concerned in establishing common points between unconscious' semantics and socially organized language-practices, pointing finally to the place of their possible break-down.
\end{abstract}

Key words: Freud; unconscious; common language.

As justificativas de Freud para o uso do conceito de inconsciente se apóiam, basicamente, em duas idéias: a primeira é que por meio do conceito de inconsciente foi possível compreender fatos até então sem sentido aparente, isto é, descobriu-se intenções ou desejos inconscientes na origem de comportamentos cujo sentido era incompreensível, até então - chamamos essa hipótese de ganho de racionalidade; a segunda, que através da conscientização desses desejos inconscientes, constatava-se que eles perdiam o efeito perturbador sobre a vida do indivíduo, pois tornava possível, a ele, atuar sobre um conflito que se achava, até então, fora do alcance de sua consciência - chamamos essa hipótese de terapêutica.

Essas duas idéias se encontram no início da teoria e constituem, mesmo, seu ponto de partida. É elucidativo apontar, nesse sentido, para o distanciamento de Freud com relação à hipótese dos estados hipnóides e de Breuer, com quem ele tratava e estudava seus primeiros casos clínicos de histeria. Até então, cabia ao médico tratar dos sintomas histéricos, mas não da cura da histeria, já que a causa dos estados hipnóides seria de origem hereditária e, portanto, encontrava-se aquém do campo da psicologia. Para Breuer, tratava-se apenas de trazer para a consciência representações vividas em estados hipnóides, impedidas, por isso, de adequada ab-reação (motora ou lingüística); isto é, o afeto dessas representações não podia tramitar livremente até sua descarga através do aparato somático porque sua vivência ocorrera em

1 Este trabalho é uma versão modificada de parte da tese de doutorado do autor, Introdução ao Pensamento de Merleau-Ponty: Contrapontos com Freud e Wittgenstein. Campinas, UNICAMP, 1998, inédita.

2 Endereço: Av. Bandeirantes, 3900. CEP: 14040-901 Ribeirão Preto SP. E-mail: reinaldo@ ffclrp.usp.br estado hipnóide. Freud jamais abandonou, nem deixou de enfatizar o aspecto energético na origem de todos os problemas psíquicos. Mas quando ele descobre na origem das representações inconscientes hipertensas um processo de repressão decorrente de um conflito de representações, ele abre um campo de pesquisas sobre o sentido dos sintomas do paciente que não existia em Breuer.

A teoria freudiana sobre o inconsciente passou, porém, tanto do ponto de vista da racionalidade, quanto do ponto de vista terapêutico, de uma visão mais simplista sobre seu sentido e mais otimista sobre sua cura, para uma visão mais complexa e menos otimista, respectivamente. Assim, antes da noção de sexualidade infantil, bastava rememorar o trauma ou o desejo inconsciente para que a força da representação intensa se desfizesse, a despeito de Freud falar, com o abandono da metáfora do "corpo estranho", de um complexo de representações ligadas em torno da representação reprimida; localizada a representação hipertensa, podia-se desfazer o seu sintoma.

Na medida em que se passa à idéia de estruturação dos investimentos da libido e de seus conflitos, passa-se a investigar uma estrutura de comportamento, ou o complexo de Édipo, que tem, justamente, esse papel estruturante. Ou seja, passa-se da simples idéia de rememoração de uma representação para a de explicitação de uma estrutura (mais ou menos conflituosa) de sentidos vividos, o que significa tanto um aumento de complexidade na questão de seu sentido, quanto um aumento de dificuldade na superação de seus conflitos, pois agora, afinal, é uma forma de vida que se encontra em questão (um caráter, também poderíamos dizer), e não mais apenas um fato isolado.

Ora, ainda que as idéias de ganho de racionalidade na compreensão do comportamento humano (essa razão agora presente, como enfatiza Foucault (1976/1993), até mesmo 
nos lugares tradicionalmente concebidos como exteriores a ela: as forças cegas dos instintos que a razão devia controlar) e de terapia ou "eficácia" do tratamento encontrem-se imbricadas na formação da teoria, devemos distingui-las do ponto de vista epistemológico. Com Wittgenstein (1969/1972) distinguimos entre critérios de verdade e eficácia ou resultados práticos de uma teoria, ou seja, não é porque uma teoria funciona ou tem eficácia que ela é verdadeira. Em outros termos, os critérios de verificação e de aplicação de uma hipótese ou teoria fazem parte de um jogo de linguagem, cujas regras determinam as condições de sentido e de verdade. São as práticas lingüísticas que determinam, pois, as condições em que tais e tais resultados confirmam ou não uma teoria. Ora, a psicanálise, conforme notaram Popper (1963/ 1967) e o próprio Wittgenstein (1966/1982), não se conforma com os padrões de cientificidade de uma teoria, isto é, não se conforma com os critérios estabelecidos por nosso jogo de linguagem chamado "ciência". Para Popper, como se sabe, a linguagem psicanalítica está mais próxima da linguagem dos mitos, ou, como diz Wittgenstein, não é Freud quem explica os mitos antigos, ele propõe um novo mito: localiza as origens, tragifica a vida, seduz... (1966/1982, p. 9) ${ }^{3}$ (características da linguagem mitológica). Nesse sentido, a isso que Freud chama de ganho de racionalidade, pensando incorporar a psicanálise às teorias científicas em geral, Wittgenstein chama de teoria estética, que, se representa um ganho ou formação de sentido sobre fatos até então incompreensíveis, não é do mesmo tipo que o que representa a explicação científica. A diferença entre "explicação" estética e explicação científica, diz Wittgenstein, é que enquanto a explicação na ciência é obtida experimentalmente, a explicação estética

3 Wittgenstein dedicou parte de suas reflexões ao caráter sedutor da teoria freudiana. Compare a diferença de atração: sonho como realização de desejos e sonho como memórias de fatos ocorridos: "Nós não sentimos que memórias pedem por uma interpretação do mesmo modo como sentimos a respeito dos sonhos" (1966/1982, p. 5), ou ainda, "os sonhos parecem pedir ao sonhador uma interpretação, parecem ter algo enigmático" (p. 4). Granier (1981), em contrapartida, assume positivamente o caráter mitológico da teoria: "Que procura Freud, em última instância? Nada mais - segundo suas próprias declarações - que pensar 'o homo natura'. Através desta alusão expressa à natura, a reflexão freudiana mostra que ela ultrapassou largamente o quadro da experiência clínica e da investigação sócio-cultural onde suas 'hipóteses convencionais' são compatíveis com as normas da ciência. Freud (1981) está, aliás, bem consciente disso, já que ele não recua diante desta confissão capital: 'a teoria das pulsões é, por assim dizer, nossa mitologia, as pulsões são essências míticas, formidáveis em sua indeterminação. Nós não podemos perdê-las um só instante de vista, em nosso trabalho, e nós não somos, entretanto, jamais seguros de apercebê-las com acuidade'. O mito não é de modo algum um agregado de fantasias; muito pelo contrário, Freud lhe restitui, aqui, sua potência primeira de desvelamento, face a uma realidade que se furta ao saber objetivo da ciência, requer o simbolismo do pensamento (...) Ligada assim à pulsionalidade do id como natureza, a mitologia designa, portanto, aos olhos de Freud, o discurso sobre as origens, o discurso do originário. E o id pulsional é então, precisamente, o originário, mesmo: isso do qual procede o conjunto da vida psíquica, com todas as suas ramificações (...)". Granier aproxima o projeto de investigação freudiana e sua noção de id, da filosofia de Nietzsche e sua noção de "caos" (pp. 100-101). pressupõe necessariamente a concordância pessoal daquele a quem ela é dada (1966/1982, p. 10).

Também Merleau-Ponty (1949-1952/1988), sem dúvida mais receptivo à teoria psicanalítica, apontou para a possibilidade de separação entre teoria e prática psicanalíticas: a teoria pode estar correta e a prática ser ineficiente, assim como a prática ser eficiente e a teoria incorreta. Ou seja, diz Merleau-Ponty, é claro que algo ocorre na relação analítica entre médico e paciente, mas disso não decorre que a psicanálise seja a melhor teoria para a sua compreensão; ao contrário, em De Mauss a Claude Lévi-Strauss (1960/1984), Merleau-Ponty sugere que a etnologia nos mostra que a psicanálise pode ser a nossa "feiticeira".

Em resumo, enquanto a ciência mais "especulativa" encontra meios (às vezes limitados) de se vincular aos padrões de experimentação científica (não fosse assim não seria considerada de padrão científico), dos quais fazem parte, por exemplo, a possibilidade de repetição da experiência, o acesso intersubjetivo à observação, ou a possibilidade de previsão (tratamento científico do sonho, segundo Wittgenstein: a partir do relato de um sonho, predizer o que virá à memória do sonhador - 1966/1982, p. 5), a psicanálise restringe-se ao campo de experiência entre duas pessoas, médico e paciente. Ou, como diz Merleau-Ponty (1960/1984), "mesmo em suas formas mais canônicas e respeitosas, a psicanálise só se reúne à verdade de uma vida através da relação entre duas vidas, na atmosfera solene da transferência, que (se existir) não é um puro método objetivo" (p. 202).

É verdade, em contrapartida, que Freud procura se defender da crítica de arbitrariedade das representações inconscientes - que afirma a possibilidade delas serem resultado da análise, e não conteúdos representacionais autênticos e inconscientes - afirmando que o médico pouco pode fazer com conteúdos que não expressam os conflitos inconscientes do paciente, e que a análise não avança enquanto não se caminha na direção do inconsciente; ou, como enfatiza Wäelhens (1990), enquanto o sujeito não se reconhece de fato nas representações que se elaboram na análise, o que implica, por sua vez, que qualquer sucesso em análise leva a um ganho na compreensão sobre a própria vida (p. 147). Essas objeções, porém, não alteram as razões que acabamos de apresentar.

Ou seja, entramos, com a psicanálise, em uma formação de sentidos cuja eficácia simbólica pode ser evidente para seus adeptos sem que se possa estabelecer, aí, critérios de cientificidade da teoria.

Ora, apesar de se colocar sob "suspeita" o quadro teórico que organiza a experiência clínica - o que não significa, para falar como Popper (1963/1967), que seus conceitos não apontem para fatos importantes -, e de se ter de aguardar ainda por métodos de investigação mais adequados aos nossos padrões de cientificidade (desde que se queira introduzir a psicanálise no quadro das ciências naturais, como Freud, ao que parece, pretendeu fazê-lo), o fato é que a psicanálise se incorporou, em parte, à nossa cultura. Por meio dela, fomos habituados a pensar sobre algumas questões que parecem, hoje, incorporá-la à nossa visão comum de homem. Entre outros, são temas nos quais se nota fortemente a sua 
presença: a importância da sexualidade; sua repressão e seus distúrbios de ordem somática e psíquica; a intencionalidade que não se apóia na consciência e que alargou o campo de interpretação do sentido das ações humanas, as relações de identificação na família, estruturantes da personalidade.

Essa incorporação das idéias da psicanálise à nossa visão comum de homem é um fato cujas proporções chamou a atenção de Wittgenstein (1966/1982) sobre o poder de atração de suas idéias; de Popper (1963/1967), pelo uso excessivo da teoria na explicação de qualquer fato humano; e de Foucault (1976/1993), que procurou no processo histórico as razões desse prestígio. Foucault vinculou, nada mais nada menos, a psicanálise ao processo de constituição de nossa subjetividade (e de dominação dos corpos), de modo que ela representa, em parte, os princípios históricos de constituição de nossa própria identidade. Já Merleau-Ponty fez uma avaliação diferente a respeito da crescente importância teórica que a noção de sexualidade adquiriu em nossa cultura com a psicanálise, da qual ela é expressão. A sexualidade, diz Merleau-Ponty (1960/1984) na Fenomenologia da Percepção, é uma noção central na existência humana porque ela é a maneira geral como nos relacionamos com o outro e o mundo. ${ }^{4}$ Também não lhe passou despercebido, entretanto, o caráter problemático da expansão de sua institucionalização:

com maior razão, ao se transformar numa instituição, ao aplicar-se mesmo aos sujeitos ditos 'normais', cessa completamente de ser uma concepção que se possa justificar ou discutir por casos, não cura mais, persuade, modela os sujeitos conforme sua concepção do homem, tem seus convertidos e, talvez, seus refratários, não pode mais ter seus convictos. (p. 202)

Em síntese, se a psicanálise não se incorporou às nossas práticas científicas, ela mudou profundamente nossa concepção de homem. O objetivo deste ensaio é explorar parte desse significado. Mais precisamente, explicitar a principal característica disso que Freud chamou de ganho de racionalidade com a hipótese do inconsciente, e que para nós se mostra na questão de sua relação com a semântica da linguagem comum.

Com isso, não pretendemos negar a inspiração científica dos trabalhos de Freud, mas apontar os efeitos da teoria freudiana para uma teoria da significação em geral, que inspiram uma Hermenêutica, uma Antropologia e até mesmo, uma Ontologia, caminhos percorridos pelo pensamento ocidental depois de Freud (também não é nossa intenção sugerir que o "bom" Freud pertence a esta tradição e não à outra, que o aproximou de uma Ciência Natural). Por último, vale dizer que este ensaio tem o caráter de aproximação da questão da relação entre pensamento e expressão na teoria freudiana. Trata-se apenas de levantar alguns pontos para a discussão, que nos parecem relevantes para a nossa questão.

4 "Se a história sexual de um homem oferece a chave de sua vida, é porque na sexualidade do homem projeta-se sua maneira de ser a respeito do mundo, a respeito do tempo e a respeito dos outros homens" (Merleau-Ponty, 1945/1994, p. 219)

\section{Para uma teoria freudiana da expressão}

Desde o abandono da metáfora do "corpo estranho", Freud (1893-1895/1989), em Estudos sobre a histeria, começa a enfatizar a participação das representações inconscientes no sistema consciente de pensamento, visto que um corpo estranho não se vincula, propriamente com o meio. Do ponto de vista clínico, a palavra deixa de ser apenas um instrumento para se chegar ao trauma e à ab-reação deste. A palavra passa a ser vista, também, como sintoma de defesa contra a representação inconsciente reprimida (um complexo de representações com graus variáveis de ligação com a representação reprimida) para então, sobretudo a partir de $A$ Interpretação dos sonhos, ser vista como sintoma de compromisso entre a defesa que reprime o desejo segundo a moral do eu, e também como o próprio desejo que pressiona no sentido de sua satisfação. Em outros termos, o sintoma deixa de ser visto como o efeito de uma representação intensa impossibilitada de fluir adequadamente devido à sua vivência em estado hipnóide (o que impossibilitava a sua associação com outras representações) e passa a ser visto como o resultado do próprio conflito de representações e, finalmente, como o compromisso entre as exigências do impulso e da defesa.

Desde o princípio da teoria ficou claro, a Freud, que o psiquismo não podia ser considerado apenas no seu aspecto consciente, e se nos seus primeiros casos clínicos a "repressão" de idéias contrastantes com a moralidade do eu ainda era um processo mais ou menos consciente, a teoria logo caminhou na direção da idéia de um processo de repressão automática de representações que não se tornavam conscientes. No Projeto de Psicologia, de 1895, essa idéia já aparecia com toda a clareza.

O Projeto representa a primeira grande tentativa de Freud de elaboração de um modelo do aparelho psíquico, e quando veio à luz reacendeu o debate dos intérpretes sobre a questão do fisicalismo no pensamento freudiano. Há relativo consenso no reconhecimento, entretanto, de que no Projeto já se encontrava presente boa parte da teoria desenvolvida posteriormente (Monzani, 1989). Ora, o aspecto a salientar para a nossa questão é que o conceito de inconsciente, aí, é bastante alargado. Não apenas as representações contrastantes com a moralidade do eu, que sofreram repressão, são mantidas inconscientes e com acesso negado à consciência, mas a maior parte do funcionamento do psiquismo é inconsciente (como se sabe, essa é uma das razões da insuficiência da primeira tópica para a descrição do aparelho psíquico); de modo que assistimos a duas noções de inconsciente: a de representações inconscientes reprimidas e a de funcionamento psíquico inconsciente.

O Projeto postula, em síntese, que o que se apresenta à consciência é resultado de um processo inconsciente que comanda o itinerário da energia psíquica segundo sinalizações de sentido armazenadas no aparelho de memória, que correspondem a dois princípios de organização: o princípio de realidade, que deve levar em conta o mundo exterior (fazer a distinção entre percepção e imaginação), e o princípio do prazer, que visa à descarga da excitação. No caso, a exci- 
tação psíquica deve ser descarregada associando-se a representações adequadas para esse fim, evitando, ao mesmo tempo, representações desencadeadoras de desprazer. Isto é, pode haver conflito entre representações no processo de descarga. $\mathrm{O}$ exemplo mais notório é o da moralidade contrária aos interesses sexuais. O outro exemplo é o caso das representações associadas à dor, que devem também ser evitadas. De modo que o ego seria um sistema de ocupações neuronais fixas e variáveis para o cumprimento dessas duas tarefas sob o princípio do prazer: descarregar adequadamente as excitações no seu interior, evitando representações desencadeadoras de desprazer. Como a maior parte desse funcionamento não é consciente, podemos falar em um "cálculo" inconsciente de distribuição e descarga de excitações segundo o princípio do prazer.

Para o nosso propósito, o mais importante é apontar que as lacunas ou desvios de sentido são resultado desse processo. (Por isso, e em contrapartida, diz Freud (1893-1895/1989), quanto mais nos aproximamos dos processos de conhecimento, mais nos afastamos desse funcionamento comandado pelo princípio do prazer).

Com isso, chegamos a uma teoria da expressão em Freud. Por um lado, temos representações inconscientes que buscam expressão no pré-consciente. Por outro lado, temos um ego que se defende da emergência no pré-consciente de representações afetivas contrastantes com sua moralidade, o que modifica a sua expressão. Assim, surge uma gama variada de sentidos, desde aqueles considerados 'normais', onde há acordo sobre os significados vividos na comunidade lingüística (para falar à luz da teoria dos jogos de linguagem, de Wittgenstein), até os patológicos. Nestes, o desacordo é manifesto, por isso eles são incompreensíveis para os membros da comunidade. São eles os sintomas, as obsessões, as fobias, onde os objetos eleitos para representar o desejo reprimido na cadeia associativa do pensamento escapam a seus usos convencionais (por isso mesmo são escolhidos, pois satisfazem à censura). Dessa forma, a representação originária do desejo fica inconsciente, ou a representação substituta, à qual o desejo se liga sob o efeito da censura, torna-se consciente.

Aparentemente, chegamos, também, à idéia de um "uso singular da linguagem" na manifestação dos desejos inconscientes, pois esses objetos eleitos para representarem os desejos reprimidos remetem a experiências e "significados singulares" que não correspondem a seu significado comum. Eis o porquê, mesmo que se fale em símbolos oníricos universais, de estes não bastarem para revelar o sentido dos sonhos, pois há outros que se apóiam na singularidade da experiência de cada um. ${ }^{5}$ Por exemplo, no caso de Emma, Estudos sobre a Histeria (Freud, 1895/1989) a impossibilidade de ela entrar sozinha em lojas (comportamento sem sentido para a comunidade lingüística) foi associada, em um

5 Freud (1916-1917/1989) afasta a possibilidade de interpretação dos sonhos apenas através dos símbolos, independente das associações de idéias produzidas na análise pelo sonhador sobre o próprio sonho: “(...) Exponho-o porque pode mostrar-lhes quão inacessível à compreensão é, em geral, um sonho antes que o sonhador nos tenha dado primeiro momento da análise, ao riso dos balconistas que debochavam de seu vestido (primeira representação que conferia em parte sentido ao seu comportamento, considerando-se a fragilidade do ego na infância); a seguir, descobriuse que todas essas representações (loja, balconistas, vestido, deboche) associavam-se ao atentado sexual que Emma recebera em tais circunstâncias na sua infância (representação que confere, então, pleno sentido ao seu comportamento). Essas representações formavam um complexo que impedia a ligação do medo de Emma de entrar em lojas sozinha à representação do atentado sexual por ela sofrido; tais representações encontravam-se reprimidas porque o acesso a elas se aproximava da rememoração da representação principal. Na medida em que eram acessadas na análise, desencadeavam desprazer porque se aproximavam do núcleo da experiência ou representação traumática; serviam, pois, como sinal de alerta e impedimento do fluxo da energia psíquica nessa direção. Naturalmente, a ligação entre essas representações fazia parte apenas da experiência vivida por Emma, e daí a idéia de um sentido individual [como enfatizava Politzer, (1928/1998), junto de sua crítica à noção freudiana de inconsciente], diferente dos sentidos da linguagem comum.

Como o inconsciente é formado por representações recalcadas que não apenas atraem outras representações (a representação do "atentado sexual" atraiu as representações de loja, deboche, vestido, balconistas), como procuram sua manifestação no sistema consciente através de representações substitutas (que representam o compromisso entre a defesa e o desejo, sobretudo após A Interpretação dos Sonhos), também podemos dizer que parte das motivações do eu lhe são totalmente desconhecidas. Ou ainda, que a própria estruturação do sujeito, que configura seu estilo de vida, faz-se, em grande parte, a partir de lugares que se encontram fora do domínio da consciência, e depende, como Freud mostrou ao longo de toda a sua teoria, do montante de energia psíquica que se encontra em jogo nessas instâncias.

Isso fica claro quando analisamos o que representa o sentido consciente, após a segunda tópica. Representa, além do sentido perceptivo (que depende mais ou menos da memória, conforme se entenda o sistema consciente ligado diretamente ou não aos sinais do mundo exterior ${ }^{6}$ ), a participação de outras duas instâncias psíquicas, o id e o superego. Do superego, embora em algum momento e de alguma forma seu sentido tenha sido consciente - condição para a sua

suas referências sobre ele. No fundo, suspeito, vocês consideram que a interpretação de sonhos por substituição do significado simbólico é o ideal, e gostariam de deixar de lado a técnica de associação; proponho-me afastá-los desse erro pernicioso" (v. 15, p. 170).

6 No Projeto, as excitações provenientes do mundo exterior que atravessam $P h i$ (neurônios perceptivos) não estão em contato direto com os neurônios da consciência (w), porque passam antes pelo sistema Psi (neurônios da memória), o que significa que a memória desempenha um importante papel na percepção - esse mesmo modelo encontramos no capítulo VII d'A Interpretação dos Sonhos (Freud, 1900/ 1989). Na carta 39 a Fliess (1887-1902/1981), entretanto, o sistema ômega (composto de neurônios w) é colocado entre $P h i$ e $P s i$, o que aparentemente retira parte da importância da memória no sentido da percepção. 
introjeção -, pode-se dizer que ele atua em grande parte de forma inconsciente na elaboração dos novos sentidos. Quanto ao id, este encerra tanto representações reprimidas que em algum momento foram conscientes, quanto representações que nunca se tornaram conscientes - por definição sua atuação é inconsciente. A idéia, então, é novamente acrescentar ao sentido público da percepção, organizado por práticas lingüísticas comuns, um conjunto de sentidos ligados às experiências de cada um, o que pode até, como no caso de Emma, romper com o sentido comum do comportamento. No caso, o sentido da sua sensação de medo está fora das circunstâncias comuns nas quais o conceito de "medo" é empregado, por isso ele não faz sentido nem para a própria Emma (a não ser justamente pelo fato de ela considerá-lo 'estranho' ou 'anormal'). Seu comportamento só fará sentido quando a verdadeira representação que lhe confere o sentido socialmente aceito aparecer ao lado da representação substituta. Esta só responde às necessidades econômicas do psiquismo (da satisfação do desejo e da defesa, ao mesmo tempo) de tal forma que a falta de sentido de seu comportamento decorre do seu rompimento com as regras da linguagem comum, e só será compreendido quando for reintegrado a ela.

Para uma teoria da expressão freudiana é importante frisar, além disso, a diferença de funcionamento dos sistemas psíquicos. ${ }^{7}$ No inconsciente vigora o processo primário de descarga de energia, um estado no qual assistimos à maior liberdade de trânsito de energia entre as representações - daí os termos "condensação" e "deslocamento" empregados por Freud. ${ }^{8}$ No pré-consciente, um mínimo de coerência entre as representações é imposto pelo processo secundário de pensamento; aqui, ao contrário do inconsciente, em que vigora apenas o princípio de prazer, encontra-se também o princípio de realidade, que, se do ponto de vista econômico está a serviço do princípio de prazer (visa descarregar as excitações), do ponto de vista do sentido submete o princípio de prazer à realidade do mundo.

Podemos tomar a relação entre sonho manifesto e pensamento latente do sonho como protótipo dessa relação entre os dois sistemas de funcionamento do aparelho psíquico. Nesse caso, Freud é taxativo: não importa, para o conhecimento dos pensamentos oníricos, o sentido do sonho manifesto, ${ }^{9}$ ou não é este o objeto da análise, conquanto possa ser seu ponto de partida. No sonho, cada desejo inconsciente

7 Usamos livremente os termos da primeira e segunda tópicas freudianas, conforme a sua pertinência para a questão em discussão, marcando suas diferenças, quando necessário; embora os termos da segunda tópica tenham dado maior coerência à teoria - o caso mais explícito parece ser o das operações inconscientes no ego -, eles não são necessariamente excludentes dos termos da primeira tópica. Ver essa discussão em Monzani (1989).

8 A não ser no caso de angústia, que representa um caso limite de energia não ligada a nenhuma representação [o outro seria, segundo Monzani, (1989), o momento preliminar de formação da pulsão, "esse 'conceito limite' que aponta para o momento mesmo onde os processos energéticos orgânicos transformam-se em processos energéticos psíquicos" - p. 94], em geral, a energia psíquica não se encontra absolutamente livre, uma vez que a representação do objeto é um dos elementos da pulsão, que indica a direção para a sua satisfação. encontra em alguma representação pré-consciente (que pode representar mais de um desejo, às vezes contraditórios) a sua manifestação; aí, impõe-se logo um princípio de coerência lógica - próprio do sistema pré-consciente -, que procura dar um mínimo de coerência ao que poderia não passar de um conjunto caótico de representações. Por isso se diz que o desejo inconsciente se manifesta em pontos nodais do sonho, e que a análise, através da livre associação de idéias, toma como objeto ou ponto de partida elementos do sonho, ao invés do texto do sentido manifesto; ou ainda, como afirmam Laplanche e Leclaire (1961/1981), que a escuta psicanalítica é lacunar e não por tradução simultânea.

A grosso modo, sabe-se que "tudo" pode ocorrer no sonho: afetos contrários podem se anular (de tal modo que sonhos ou partes indiferentes destes podem encerrar a realização de desejos contrários), afetos podem se deslocar entre representações (de tal modo que representações intensas no sonho podem ser insignificantes do ponto de vista do desejo inconsciente), e representações conscientes do sonho encerram uma gama maior de representações inconscientes que inclusive podem ser contraditórias. Ora, a despeito de todas essas possibilidades, a análise dos sonhos baseia-se no princípio de livre associação de idéias, que tem, como pressupostos, a tese do "determinismo psíquico", e a tese de que um afrouxamento da censura nos leva às manifestações mais espontâneas e verdadeiras dos próprios desejos.

A idéia de que no uso da linguagem comum, com seus significados manifestos encerram-se sentidos inconscientes alheios à compreensão do próprio sujeito, parece apontar para o que Laplanche chama de estado de incomunicação das manifestações inconscientes, que parecem atender apenas à necessidade de "satisfação do desejo". ${ }^{10} \mathrm{E}$ assim, curiosamente, como sugerido, parece que nos encontramos com a crítica de Wittgenstein à possibilidade da existência de uma linguagem privada.

Não podemos nos estender, aqui, a essa crítica, mas ela parece apontar, sobretudo, para o caráter pragmático da linguagem. A saber, procura mostrar que a linguagem se insere em uma forma de vida, e que se destina à nossa relação com o mundo e o outro, e não a uma experiência "interior" a que, supostamente, diz que este apenas o seu portador teria acesso ao seu significado. Wittgenstein referindo-se ao significado da palavra "privado", diz que este apenas aponta para o portador da vivência, e não para uma relação epistemológica privilegiada, pois o sentido da vivência é determinado pelas práticas lingüísticas da comunidade. Por isso eu só "sei" o que estou sentindo, só posso falar do que sinto, porque aprendi em uma comunidade a empregar determinadas palavras em circunstâncias socialmente determinadas.

9 Nesse ponto, a observação de Wittgenstein (1966/1982), de que o trabalho de interpretação do sonho se compara ao preenchimento dos espaços vazios de uma tela que pintamos, não parece correta.

10 "Isso quer dizer provavelmente que 'au début', na gênese do inconsciente, havia um fenômeno de comunicação que em seguida se fechou sobre si mesmo, a comunicação tornando-se então "circulação", (Laplanche, 1981, p. 124). 
Em síntese, porque vivemos em comunidade, nosso comportamento é guiado de forma soberana pela linguagem comum. Ou, ainda, a importância do outro é a medida da importância da linguagem comum em nossas vidas.

Gostaríamos de destacar dois pontos da presente exposição até aqui: em primeiro lugar, nossas representações conscientes não são as representações mais apropriadas às nossas verdadeiras intenções, que por isso são inconscientes, uma vez que uma intenção se mostra no objeto visado; em segundo lugar, o sentido do nosso comportamento se dá segundo as regras da linguagem comum, não há outro sentido além desses, mesmo que vividos inconscientemente.

Ou seja, se encontramos em Freud um alargamento da noção comum do sentido vivido (noção que não explica, naturalmente, o sentido dos comportamentos patológicos ou dos atos falhos na vida cotidiana, simplesmente os considera sem sentido), não encontramos uma ruptura com a sua semântica; ou melhor, a ruptura com a semântica da linguagem comum representa apenas o transporte dessa mesma semântica para outro lugar, o inconsciente.

Mesmo quando Freud não fala em despistamento ou disfarce (em relação à linguagem comum), mas em uma forma de expressão própria dos processos primários, ele o faz ora remetendo a questões de ordem econômica (estado de energia livre no qual as relações de sentido são mais frouxas), ora a questões de ordem simbólica, mas para dizer que se tratam de formas arcaicas de expressão herdadas filogeneticamente, o que significa que elas faziam parte, outrora, das formas de expressão comum. Em outros termos, não saímos da teleologia da linguagem comum.

Por isso, Merleau-Ponty, em Fenomenologia da Percepção, acompanhando Politzer (1928/1998), coloca que o modelo freudiano do inconsciente representa um cartesianismo às avessas, e contrapõe a isso a idéia de um simbolismo originário presente em nossas relações que não remete ao simbolismo da linguagem comum. Para Politzer, a psicanálise teria descoberto a existência de sentidos concretos ou individuais irredutíveis a esses da semântica comum. Ocorre que na tradução desse sentido originário para a forma da linguagem comum (que se faz em análise), Freud teria perdido sua originalidade, porque pressupôs a mesma estrutura narrativa desenvolvida em análise na sua origem, só que de forma inconsciente. Dois pressupostos levaram Freud a essa interpretação, segundo Politzer: o do realismo, que o levou a buscar em outra instância psíquica a localização desses sentidos; e o da prerrogativa da estrutura da narrativa na origem de todo comportamento com sentido, como se só fosse possível viver com sentido, diz Politzer, o que antes é pensado na forma da narrativa (daí a hipótese da existência de um conteúdo representacional de pensamentos latentes ao lado do conteúdo manifesto do comportamento).

Do ponto de vista semântico, no ego, o modelo freudiano do inconsciente demonstraria um conjunto de representações socialmente organizadas. No id, seria um conjunto de representações cuja teleologia seria a mesma da linguagem comum. No ego, as representações formam uma gestalt em que vigora o princípio da realidade ou princípio lógico do pensamento, o que não ocorre no id. Neste, o sentido de uma representação não interfere no sentido das outras (por isso não há negação, no id), e há maior facilidade de deslocamento das representações visadas. Em outros termos, no id predomina a necessidade de descarga pulsional, em detrimento do sentido visado, que nem por isso deixa de representar a teleologia do processo da descarga energética.

Essa soberania dos significados da linguagem comum presente na noção freudiana de inconsciente é encontrada tanto na sua análise dos sonhos, como na análise de toda ação humana em geral. Como se sabe, Freud atribui ao trabalho do sonho justamente essa transformação do pensamento desiderativo (que vinculamos à teleologia da linguagem comum) para a sua forma alucinada de satisfação do desejo. No caso das ações ou do comportamento humano em geral, estes pressupõem processos anímicos inconscientes e conscientes da mesma forma ditados por ela.

\section{Os possíveis lugares da ruptura. Formas arcaicas de expressão}

Até aqui exploramos ao máximo a aproximação entre as semânticas do inconsciente e da linguagem comum. Todavia, passamos por alto a questão da regressão a formas arcaicas de expressão, da qual destacamos apenas as formas herdadas filogeneticamente, enquanto as formas pertencentes à história da infância individual parecem representar um entrave à assimilação global da semântica do inconsciente e conseqüentemente, de todo sentido do comportamento humano - à semântica da linguagem comum.

É elucidativo retomar a questão da regressão do processo psíquico por meio das Conferências de Introdução à Psicanálise (Freud, 1916-1917/1989), na parte II, referente ao sonho. Há uma regressão tópica, que representa a regressão dos pensamentos para as imagens perceptivas, ao invés de sua progressão até a expressão de palavras; há uma regressão formal a formas arcaicas de expressão do pensamento; e há uma regressão de conteúdos dos pensamentos, uma vez que os sonhos são, em sua maior parte, realizações de desejos infantis.

Nas hipóteses de regressão tópica e formal do pensamento do sonho, é curioso notar que para Freud o sentido do pensamento antecede sua forma de expressão, assim como de certo modo parece que esta forma lhe é indiferente. Em outros termos, o sentido do pensamento parece em boa medida exterior à linguagem.

À hipótese da regressão tópica (que se faz através da alucinação do desejo pensado) poderíamos levantar as mesmas objeções que Merleau-Ponty (1945/1994) fez ao intelectualismo presente nas análises da linguagem. A crítica de Merleau-Ponty visa apoiar o significado da linguagem na própria fala ou expressão: eu não penso antes de falar, a fala é a realização do próprio pensamento. Há uma intenção de significação que se realiza na própria expressão, e não uma representação de que a expressão seria a tradução. Por que pressupor, nesse sentido, a necessidade da antecedência do pensamento para a elaboração do sonho? Não bastaria a 
pulsão e a alucinação do objeto, que decorre da ausência do princípio de realidade no estado de sono? Algo como o princípio dos devaneios diurnos, em que a pressuposição de pensamentos anteriores à imaginação representa um pressuposto (intelectualista) que poderia ser economizado.

Mas o presente interesse está na regressão a formas arcaicas de expressão. Por meio dela fica claro tanto a relação entre sentido inconsciente e linguagem comum como o lugar de sua ruptura. Considere-se, a esse respeito, a noção freudiana de símbolo: "chamamos simbólica a uma relação constante dessa índole entre um elemento onírico e sua tradução, e ao elemento onírico, mesmo, um símbolo do pensamento onírico inconsciente" (1916-1917/1989, p. 137). Trata-se, como enfatiza Freud,

de conhecimentos inconscientes, de conexões conceituais, de comparações entre objetos diversos, que permite que se possa substituir de modo constante um pelo outro. Estas comparações não se estabelecem como algo novo de cada vez, mas já estão disponíveis, prontas de uma vez por todas; é o que resulta de sua concordância em diversas pessoas, concordância esta que talvez se dê apesar das diferenças de idiomas. (p. 151)

Qual a origem desses símbolos universais? Ora, para Freud (1916-1917/1989) (também no que diz respeito às fantasias de castração e sedução, e às emoções), o que não pertence à história do indivíduo faz parte de sua herança filogenética. Ou seja,

A pré-história a que o trabalho do sonho nos reconduz é dupla: em primeiro lugar, a pré-história individual, a infância; $e$ por outro lado, na medida em que cada indivíduo repete abreviadamente em sua infância, de alguma maneira, todo o desenvolvimento da espécie humana, também esta outra préhistória, a filogenética. Poder-se-á distinguir nos processos anímicos latentes a parte que provém do tempo primordial do indivíduo da que provém da filogenética? Não o creio impossível. Assim, parece-me, a referência simbólica, que o indivíduo em nenhum caso aprendeu, tem justificado direito que se a considere uma herança filogenética. (p. 182)

Freud (1916-1917/1989) nos remete, assim, para as origens das linguagens primitivas, e recorre a um investigador chamado Hans Sperber para reforçar sua idéia. Segundo Sperber, diz Freud, "necessidades sexuais tiveram a máxima participação na gênese e ulterior formação da linguagem" (p. 152). Com o tempo, outras atividades foram sendo associadas às mesmas raízes lingüísticas, que, finalmente, perderam seu significado sexual originário. Com o sonho, é possível voltar a essas mesmas significações primitivas em que "há em número tão extraordinário símbolos para o sexual" (p. 153). Isto é, encontraríamos nos sonhos formas de expressões primitivas, herdadas filogenéticamente, que, se são incompreensíveis para a nossa linguagem comum atual, eram de conhecimento público no passado.

Daí a conclusão:

os pensamentos latentes não são mais do que os pensamentos conscientes, que bem conhecemos, de nossa vida de vigília; o novo modo de expressão resulta-nos incompreensível por muito de seus traços. Dissemos que ele remonta a estados de nosso desenvolvimento intelectual superados a muito por nós, à linguagem figurativa, à referência simbólica, quiçá a condições que existiram antes que se desenvolvesse nossa linguagem discursiva. (Freud, p. 182)

O que significa, em contrapartida, que "mediante um estudo mais profundo do trabalho do sonho poder-se-ia obter valiosas aclarações sobre o início pouco conhecido de nosso desenvolvimento intelectual" (Freud, 1916-1917/1989).

A questão da regressão às formas arcaicas de expressão que pertencem à história da infância individual, parece, no entanto, representar o entrave na aproximação que fizemos entre a semântica do inconsciente e a semântica da linguagem comum, o que fica claro na questão da regressão material dos sonhos:

A regressão do trabalho onírico não é só formal mas também material. Não só traduz nossos pensamentos a uma forma primitiva de expressão, mas também convoca às peculiaridades de nossa vida anímica primitiva, a velha prepotência do eu, as moções iniciais de nossa vida sexual e ainda nosso velho patrimônio intelectual, se é que podemos conceber desse modo a referência simbólica (...) e então nossas representações sobre o inconsciente se modificam e ampliam. Inconsciente já não é mais um nome para o latente em um dado momento; o inconsciente é um reino anímico particular, com suas moções de desejo próprias, seus próprios modos de expressão e seus mecanismos anímicos específicos, que em nenhuma outra parte estão em vigor. Mas os pensamentos oníricos latentes, que coligimos por meio da interpretação do sonho, não pertencem a esse reino; são muito mais tal como poderíamos pensá-los na vigília. São, não obstante, inconscientes; como se resolve então esta contradição? (Freud, 1916-1917/1989, pp. 193-194). Fazendo a distinção entre o caráter inconsciente dos pensamentos oníricos latentes e o inconsciente que provém daquele reino do infantil (p. 194).

Ora, não são os pensamentos arcaicos da humanidade que nos interessam aqui, porque estes podemos ligar à semântica das linguagens comuns passadas. $\mathrm{O}$ que nos interessa são os processos anímicos da infância. Resta saber, nesse sentido, em que medida a presença de pensamentos infantis no inconsciente nos afasta da idéia de que todos os nossos pensamentos são esses da linguagem comum (pública), passada ou atual. Eles não precedem, em parte, a sua organização pela linguagem pública comum? Podemos, aqui, esboçar o encaminhamento que nos parece correto para essa questão, e que diz respeito à questão da relação entre representação de coisa e representação de palavra na obra freudiana.

A necessidade da ligação da representação de coisa com a representação de palavra para que o pensamento inconsciente se torne consciente, diz Freud no artigo $O$ Inconsciente (1915/1989), deve-se ao fato de que processos de pensamento distanciados da percepção são carentes de qualidade. Por isso, estes não aparecem no sistema consciente, qualidade que adquirem quando se associam às imagens acústicas da linguagem. Nesse caso, podemos supor uma série complexa de raciocínios e pensamentos inconscientes sem que a consciência se dê conta disso; o pensamento por palavras, próprio do sistema pré-consciente, seria, nesse sentido, mais 
uma tradução de um pensamento inconsciente, do qual se distingue apenas na forma da representação e por ser consciente. O motivo apresentado por Freud para a necessidade da ligação entre representação de coisa e representação de palavra para que o pensamento se torne consciente é de ordem econômica.

Freud quase não distingue, pois, do ponto de vista semântico, o sentido do pensamento por imagens do sentido deste por palavras. Melhor dizendo, do ponto de vista semântico, a distinção que Freud faz entre representação de coisa e representação de palavra (nos reportamos agora ao texto sobre afasia, 1891/1983) tem mais um caráter de limitação: representações de coisa seriam abertas porque novos dados podem se juntar a esses já associados à coisa, enquanto representações de palavra teriam um significado fechado; as representações de palavra parecem não ir além, pois desse papel de fixação de alguns conteúdos representativos dados com a percepção da coisa, papel este que não pode ser superestimado do ponto de vista do significado; a imagem do seio da mãe pelo bebê, por exemplo, tem uma forma com conteúdos determinados (ainda que novos possam ser acrescentados) que não necessita do signo lingüístico para se fixar como representação do seio e enquanto tal participar da cadeia associativa do pensamento.

Nas Conferências de Introdução à Psicanálise também encontramos um modelo parecido de linguagem. A respeito do ocultamento ou despistamento do pensamento onírico latente através do sonho manifesto, Freud (1916-1917/1989) diz:

descobrem vocês aqui um novo tipo de relação entre elemento onírico manifesto e latente. O onírico não é tanto uma desfiguração do latente quanto uma figuração do primeiro, sua expressão em imagens plásticas, concretas, que tomam como ponto de partida a literalidade de certas palavras. Mas precisamente por isso é de novo uma desfiguração, pois na palavra esquecemos há muito a imagem concreta de que surgiu, e já não a reconhecemos em sua substituição pela imagem. (p. 110)

Uma relação que aproxima a linguagem das "impressões sensíveis" e que parece tomá-las como equivalentes.

\section{Conclusão}

Com isso, devemos fazer uma importante distinção em nossa aproximação do aspecto semântico da noção freudiana de inconsciente com o caráter teleológico da linguagem comum. Isto porque antes dos significados da linguagem comum há as representações de coisas a que a linguagem se liga, e são essas representações (ligadas à realidade material) o fundamento da teleologia da linguagem comum.

Assim sendo, os processos anímicos infantis já representariam um pensamento de mundo que antecipa esses presentes na linguagem comum. Nesse sentido, podem ser alheios à sua semântica.

Ora, uma vez introduzidos a precedência e o campo mais amplo de sentido das experiências sensíveis frente à sua discriminação pela linguagem (que tem, como dissemos, mais um caráter de limitação de sentido), afirma-se a presença de um sentido vivido que não se limita a esse fixado por ela. Ultrapassa-se o sentido de sua teleologia em direção a um reino de sentidos no qual os investimentos da libido e, por consequiência, o sentido do comportamento, escapam às suas razões. Desse reino anímico, podemos dizer como Freud, que ele está para a nossa linguagem, próximo da "coisa em si” kantiana.

\section{Referências}

Foucault, M. (1993). História da sexualidade 1. A vontade de sa$\operatorname{ber}\left(11^{\mathrm{a}} \mathrm{ed}\right.$.). (M.T.C. Albuquerque, Trad.) Rio de Janeiro: Graal. (Trabalho original publicado em 1976)

Freud, S. (1981). Los origenes del psicoanalisis. Cartas a Wilhelm Fliess - 1887-1902 (L.L.-B. Torres, Trad.). Em Obras Completas (4 $4^{\mathrm{a}}$ ed., Tomo III, pp. 3433-3656). Madri: Biblioteca Nueva. (Trabalho original publicado em 1950)

Freud, S., (1989). Estudios sobre la histeria (J.L. Etcheverry, Trad.). Em Obras Completas (Vol. 2). Buenos Aires: Amorrortu. (Trabalho original publicado em 1893-95)

Freud, S. (1989). Proyecto de psicología. (J.L. Etcheverry, Trad.). Em Obras Completas (Vol. 1, pp. 323-436). Buenos Aires: Amorrortu. (Trabalho original publicado em 1895)

Freud, S. (1989). La interpretación de los sueños. (J.L. Etcheverry, Trad.) Em Obras Completas (Vols. 4-5, pp. 153-214). Buenos Aires: Amorrortu. (Trabalho original publicado em 1900)

Freud, S. (1989). Lo inconciente. (J.L. Etcheverry, Trad.) Em Obras Completas (Vol. 14, pp. 153-214). Buenos Aires: Amorrortu. (Trabalho original publicado em 1915)

Freud, S. (1989). Conferencias de introducción al psicoanálisis. (J.L. Etcheverry, Trad.) Em Obras Completas (Vol. 15-16). (Trabalho original publicado em 1916-1917)

Freud, S. (1983). Contribution a la conception des aphasies: une étude critique. (C. Van Reeth, Trad.) Paris: PUF. (Trabalho original publicado em 1891)

Granier, J. (1981). Le statut de la philosophie selon Nietzsche et Freud. Revue de Métaphysique et de Morale, 1, 88-102.

Laplanche, J. \& Leclerc, S. (1981). L'Inconscient, une étude psychanalytique. Em Problemátiques IV - L'inconscient et le ça (pp. 261-321). Paris: PUF. (Originalmente publicado em 1961).

Laplanche, J. (1981). Problemátiques IV - L'inconscient et le ça. Paris: PUF.

Merleau-Ponty (1984). De Mauss a Claude Lévi-Strauss. (M.S. Chauí, Trad.). Em Merleau-Ponty, Coleção Os Pensadores. São Paulo: Abril Cultural. (Originalmente publicado em 1960)

Merleau-Ponty (1988). Merleau-Ponty à la Sorbonne - résumé de cours 1949-1952, Dijon-Quetigny, Cynara. (Originalmente publicado em 1964)

Merleau-Ponty (1994). Fenomenologia da percepção. (C.A.R. Moura, Trad.) São Paulo: Martins Fontes. (Trabalho original publicado em 1945)

Monzani, L.R. (1989). Freud: o movimento de um pensamento (2a. ed.). Campinas: Unicamp. 
Politzer, G. (1998). Crítica dos fundamentos da psicologia: a psicologia e a psicanálise. (M. Marciolino \& Y.M. Campos Teixeira da Silva, Trads.) Piracicaba: Unimep. (Originalmente publicado em 1928)

Popper, K. (1967). La ciencia: conjecturas y refutaciones (N. Míguez, Trad.). Em El desarrollo del conocimiento científico - conjecturas y refutacines. Buenos Aires: Paidos. (Originalmente publicado em 1963)

Waëlhens, A. (1990). A psicose: ensaio de interpretação analítica e existencial. (V. Ribeiro, Trad.) Rio de Janeiro: Zahar. (Origi- nalmente publicado em 1972)

Wittgenstein, L. (1972). On certainty. New York-London: Harper Torchbooks. (Originalmente publicado em 1969)

Wittgenstein, L. (1982). Conversations on Freud. Em Wölheim R. \& Hopkins J. (Orgs.), Philosophical essays on Freud (pp. 111). Cambridge: Cambridge University Press. (Originalmente publicado em 1966)

\section{Subscriptions}

Send your order for Subscriptions to the Psicologia: Teoria e Pesquisa to:

Revista Psicologia: Teoria e Pesquisa

Secretaria de Divulgação

Universidade de Brasília - Instituto de Psicologia

70910-900 Brasília - DF

BRAZIL

Rate for individuals US\$ 48

Rate for institutions RS\$ 75

Past single numbers:

US\$ 14 (individual subscriber)

US\$ 20 (institutional subscriber)

US\$ 24 (not individual subscriber)

US\$ 37 (not institutional subscriber) 